\title{
EL HABLA DE SEVILLA Y LOS DIALECTALISMOS DEL ESPAÑOL DE AMERICA
}

Rafael Cano Aguilar

1. La expresión «dialectalismos del español de América» puede ser entendida y desarrollada en modos diversos, incluso separados entre sí: tal ambigüedad, más que polisemia, nos ayudará sin embargo a descubrir algunas de las perspectivas que pueden adoptarse en el análisis de las hablas hispanoamericanas como realidad dialectal.

En primer lugar, el mismo hecho de hablar de "el español de América», según es tradición en la Filología hispánica, parece darnos una realidad diferenciada y opuesta al español peninsular (o, al menos, a su variedad principal): como es éste el considerado "normativo», no cabe duda, por tanto, de que el español americano es, en sí, un dialecto. De hecho, su descripción suele encomendarse a los tratados dialectológicos; y en general figura como dotado de entidad propia y autónoma. Sin embargo, es difícil precisar, más allá de la ubicación geográfica y su desarrollo histórico, qué es lo común de todo el español de América y sólo de él: su rasgo fonológico más acusado, la ausencia de oposición entre sibilante dental y alveolar, es compartido con el español «cisatlántico»; y ningún otro se da, como éste, en toda América. En el plano gramatical, sólo podríamos hablar en este sentido de la ausencia de vosotros y su paradigma (y quizá también de ciertas preferencias por tiempos verbales, aún mal definidas); pero también este hecho vuelve a aparecer en España. En cuanto al léxico, dejando a un lado su intrínseca inestabilidad, carecemos aún de una minuciosa geografía léxica americana; y aunque pueden observarse ciertas afinidades de vocabulario, ello no justifica el seguir hablando de que "se usa en América» una palabra que documentamos en tal o cual país o zona. Tampoco es unitaria la entonación, aunque posea por lo general mayor altura que la peninsular (aun habiendo dentro de ésta notables diferencias), y haga a los americanos fáciles de reconocer por cualquier oido español. Todo esto: escasez de rasgos distintivos comunes y abundantes divergencias internas, imposibilita hablar del español americano como de «un dialec- 
to». Pero otras consideraciones, entre las que no es la menor el que sea América la zona del mundo donde mayor número de hispanohablantes hay, nos obligarían a replantear si debe ser en verdad la Dialectología la que se ocupe prioritariamente (como hasta ahora ha hecho) del español hablado en América.

Esas divergencias internas, que configuran áreas relativamente homogéneas (en mayor o menor grado), podrían entenderse como los «dialectalismos» del español en América: las variedades que ha ido adquiriendo la lengua al entrar en contacto con otros hablares o en circunstancias especificas. Pero es otro el sentido en que, en este momento, nos interesa el término: el histórico, de modo que el español americano se nos ofrece como la continuación de unas formas de hablar español que consideramos (ahora y antes) dialectales. La base sobre la que se formó el español en América fue, en buena parte, de índole «dialectal»: es decir, respondía a una norma que, en sus aspectos más innovadores, no llegó a convertirse en la forma superior de habla; a esto se añadió el trasiego de elementos dialectales de otro origen, que habian quedado desplazados del castellano literario y modélico (o no entraron nunca en él). Los «dialectalismos» del español americano serian, en este segundo sentido, previos a él: su clasificación como tales se habria hecho sobre el español peninsular (y canario), y su presencia en América no haría sino añadir un elemento más a la localización de elementos no pertenecientes a la lengua normativa.

Ahora bien, el análisis de tales «dialectalismos» puede ilustrarnos, y mucho, sobre el modo de implantación del español en América y el mayor o menor peso de las distintas variedades originarias de habla en su configuración. No obstante, hay que reconocer que las zonas dialectales que podemos hoy encontrar en América de ningún modo reproducen las divisiones dialectales de la metrópoli: casi nunca se produce tal mimetismo cuando una lengua es trasplantada de su hábitat originario; pero además en la colonización de América no se produjo el reparto diferenciado de colonos agrupados por sus orígenes (como en parte ocurrió entre los judíos expulsados): es cierto que hubo concentraciones de andaluces en el Caribe, de vascos y castellanos viejos en una zona que va de Chile a Paraguay; pero lo que predominó fue la integración de las distintas procedencias, y, como consecuencia, la nivelación lingüística. El único intento que se ha hecho de remontar las diferencias dialectales internas de América a distintos núcleos de pobladores ha sido el que se refiere a las divergencias entre el habla del litoral y la de las altiplanicies del interior: las costas habrian sido pobladas preferentemente por andaluces, canarios y extremeños, a lo que se debería su impronta fonética meridional, mientras que el interior sería el destino mayoritario de castellanos y norteños. Esta explicación, esbozada por M. L. Wagner ${ }^{1}$, deformada a veces hasta el punto de presentarla como oposición lingüística debida a razones climáticas, fue reformulada por $\mathrm{M}$. $\mathrm{Pidal}^{2}$ en términos de índole sociohistórica: tierras de «la

1 "Amerikanisch-Spanisch und Vulgärlatein», Zeitschrift für Romanische Philologie, X1, 1920, pp. 286-312 y 385-404; «El supuesto andalucismo de América y la teoría climatológica», Revista de Filologia Española, X1V, 1927, pp. 20-32.

2 "Sevilla frente a Madrid: Algunas precisiones sobre el español de América», Estructuralismo e Historia. Miscelánea-Homenaje a A. Martinet, T. III, Univ. de La Laguna, 1962, pp. 99-165. 
flota», en contacto continuo con las modalidades meridionales que aportaba dos veces al año la flota zarpada de Sevilla, y con un tipo de vida más bien mercantil; frente a tierras del interior, en contacto sobre todo con las formas cultas metropolitanas: población de funcionarios, cortesanos, etc. En último término, como observa B. Malmberg ${ }^{3}$, lo que ocurre es que las que en la Península eran diferencias sociales se convierten en América en diferencias dialectales geográficas.

2. El carácter dialectal del español americano arrancaría, pues, en último término del hecho de que, en los momentos de su constitución inicial, el fermento sobre el que se produjo la nivelación era (o, mejor dicho, acabaría siendo) de tipo dialectal: no otra es la vieja polémica sobre el «andalucismo» del español de América. No vamos a hacer de nuevo aquí la historia de la discusión: relaciones más o menos completas han sido ya hechas por G. L. Guitarte, B. Malmberg, R. Lapesa, A. Rosenblat, Y. Malkiel, M. Danesi y otros ${ }^{4}$. Hoy la cuestión parece definitivamente asentada: tras las intervenciones, entre 1957 y 1962, de los más destacados filólogos españoles (M. Pidal, Lapesa, D. Catalán, A. Galmés, etc.) ${ }^{5}$, y tras las pormenorizadas relaciones demográficas emprendidas por P. BoydBowman ${ }^{6}$, parece no quedar duda alguna de que la base fonológica del español americano es de origen andaluz; en concreto, el fenómeno más característico, la inexistencia de sibilante alveolar apical en oposición a una dental dorsal, había surgido ya en el Reino de Sevilla mucho antes del Descubrimiento y fue llevado y generalizado a América por obra del poderoso elemento andaluz (mayoritario en los primeros años; el primero siempre, al menos durante el s. XVI). Otros fenómenos, tales como la aspiración de $-s$ o los varios relajamientos y confluencias de ciertas consonantes en posición implosiva, si bien no pueden caracterizarse como «andaluces» en sentido estricto, sí es cierto que se difundieron en América gracias a los naturales de Andalucia (lo mismo podríamos decir del «yeísmo»). Hay otras concomitancias de orden gramatical entre América y el Sur de la Península: la eliminación de vosotros, el mantenimiento del sistema casual etimoló-

3 La América hispanohablante (trad. de J. López Facal y K. Lindström), Madrid, Ed. Istmo, 1970 , p. 151 .

4 G. L. Guitarte, "Cuervo, Henriquez Ureña y la polémica sobre el andalucismo de América", Vox Romanica, XVII, 1958, pp. 363-416; Malmberg, op. cit., pp. 147-156; R. Lapesa, «EI andaluz y el español de América», Presente y futuro de la lengua española, H, Madrid, 1964, pp. 173-182 (recogido en Estudios de historia lingüística española, Madrid, Paraninfo, 1985, pp. 267-282); Á. Rosenblat, "El debatido andalucismo del español de América», El Simposio de México, México, 1969, pp. 149-190; Y. Malkiel, Linguistics and Philology in Spanish America, Mouton, The Hague-Paris, 1972 (espec. Cap. III: «Linguistic aspects of inmigration and settlement», pp. 37-47); M. Danesi, «The Case for Andalucismo reexamined», Hispanic Review, 45, 2, 1977, pp. 181-193, etc.

5 R. M. Pidal, art. cit.; Lapesa, «Sobre el ceceo y el seseo andaluces», Estructuralismo e Historia, 1, 1957, pp. 67-94 (ahora en Estudios, pp. 249-266), y «Sobre el ceceo y el seseo en Hispanoamérica», Revista Iberoamericana, XXI, 41-42, 1956, pp. 409-416; D. Catalán, «El çeçeo-zezeo al comenzar la expansión atlántica de Castilla», Boletim de Filologia, XVI, 1956-57, pp. 305-334; Á. Galmés, Las sibilantes en la Romania, Madrid, Ed. Gredos, 1962.

6 Véase su última contribución, en la que resume los resultados obtenidos y en la que relaciona sus anteriores trabajos: «Patterns of Spanish Emigration to the Indies until 1600», Hispanic American Historical Review, 56, 4, 1976, pp. 580-604. 
gico en los pronombres afijos, y quizás algún otro menos claro (p. ej. la intensidad con que un SN con de sustituye a los posesivos de $3{ }^{\mathrm{a}}, 2^{\mathrm{a}}$. personas, y 1 a plural). Todos estos aspectos han sido señalados, pero a diferencia de las cuestiones fonológicas no han merecido hasta ahora un estudio genealógico: se anota la coincidencia, o se da sin más por sentada la relación histórica. Tampoco hay un estudio específico del andalucismo léxico: hemos de limitarnos a las viejas comprobaciones de Toro y Gisbert ${ }^{7}$, a las indicaciones ocasionales de los numerosos «diccionarios de americanismos», y al agrupamiento de "Andalucismos americanos» que, en la primera edición de su obra (Vol. IV), hizo J. Corominas ${ }^{8}$; a ello ha venido a añadirse la reciente relación de T. Sandru Olteanu ${ }^{9}$, dentro de un recuento sobre el léxico regional español en América; el aspecto histórico de la cuestión no ha sido aún debidamente abordado. A pesar, sin embargo, de todas estas deficiencias, las bases establecidas hace ya dos décadas siguen firmes y, como indicaba M. B. Fontanella de Weinberg ${ }^{10}$, los nuevos estudios no modifican ya la visión de conjunto sino que se limitan a aportaciones parciales.

Convendría, no obstante, hacer algunas matizaciones a la doctrina generalmente admitida. En primer lugar, en lo que se refiere al mismo término de andalucismo: quizá no sea la denominación más adecuada para aludir a las semejanzas y a la filiación genética del español americano. Los fenómenos reseñados, con la excepción del seseo y, quizá, la ausencia de vosotros, no son exclusivamente andaluces (probablemente, ni siquiera en sus orígenes); la mayoría de ellos, además, no abarca la totalidad del territorio andaluz. En cuanto al fenómeno, éste sí andaluz, mejor conocido: la indiferenciación de sibilantes dentales y alveolares (el histórico çeçeo-zezeo, luego diversificado en "ceceo»/ «seseo»), tuvo una zona de origen muy concreta, el Reino de Sevilla y «la costa del Andaluzia»; éste era su enclave más firme en la época del Descubrimiento y la Conquista, aunque ya hubiera comenzado su expansión (hacia el resto de Andalucía, sin que llegara a conquistarla por completo, y a Canarias). Así pues, por su origen y por el sentimiento de los coetáneos, gramáticos o no (como bien puso de manifiesto A. Alonso $\left.{ }^{11}\right)$, nos hallamos ante un fenómeno "sevillano». La perspectiva demográfica apoya la idea de "sevillanismo»: de los 20.229 andaluces que cuenta Boyd-Bowman emigrados al Nuevo Mundo entre 1493 y $1600,12.566$, el $62,1 \%$, procedían de la provincia de Sevilla. Si a ésta añadimos las de Huelva y Cádiz, integrantes del mismo Reino, la proporción sube al 78,9\% (16.079) del total de andaluces: estas tres provincias, seguidas de la de Córdoba, figuran entre las diez primeras en nú-

7 «Voces andaluzas», Revue Hispanique, XLIX, 1920, pp. 313-647.

8 Diccionario crítico etimológico de la lengua castellana, 4 vols., Madrid, Gredos, 1954-57; véase ahora J. Corominas y J. A. Pascual, Diccionario crítico etimológico castellano e hispánico, 5 vols. (A-X), Madrid, Gredos, 1980-83.

9 "Sobre la contribución del elemento hispánico regional en el léxico del español de América», Estudios ofrecidos a E. Alarcos Llorach, 5, Universidad de Oviedo, 1983, pp. 173-195.

10 «Interpretaciones teóricas y estudios documentales sobre la evolución de las sibilantes españolas», Romance Philology, XXXI, 2, 1977, pp. 298-308.

11 «Historia del ceceo y del seseo españoles», en De la pronunciación medieval a la moderna en español, II, Madrid, Gredos, 1969, pp. 47-144. 
mero de emigrantes a América (siendo la primera Sevilla, con más del doble que la siguiente). De esta forma, los sevillanos constituyeron el $22,9 \%$ del total de emigrados en el período 1493-1600 (54.881), los naturales del Reino de Sevilla en su conjunto el $29,2 \%$. Pero no hay que olvidar que de los procedentes de la provincia de Sevilla, eran 10.638 , el $84,6 \%$, los que se declaraban nacidos en la misma ciudad de Sevilla; por otro lado, como destaca Boyd-Bowman, de la ciudad de Sevilla procedía, aparte el 19\% del total de emigrantes, el $39 \%$ de las mujeres (entre las mujeres siempre fueron mayoritarias las andaluzas), así como aproximadamente el $50 \%$ de los comerciantes. Junto a otros datos: importancia del comercio y el transporte, prestigio cultural siempre creciente, etc., todo esto nos muestra cómo América, durante la primera centuria de su vida hispánica, no podía dejar de conformarse según patrones sevillanos ( $\mathrm{y}$ esto no sólo en los primeros años o «período antillano»: los datos de Boyd-Bowman muestran cómo el porcentaje de andaluces y sevillanos estaba volviendo a subir hacia 1600); BoydBowman insiste también en el predominio de mujeres andaluzas, y sevillanas en particular, para intentar explicar por qué las pautas de comportamiento social y lingüístico que surgían en buena parte de las nuevas colonias reproducían los modos sevillanos. Esta idea de «sevillanismo», latente en toda la polémica del «andalucismo", se desprende ya de D. Catalán (en su trabajo de 1958: Génesis del español atlántico. Ondas varias a través del Océano), está en la base, y en el título, del famoso estudio de M. Pidal de 1962: "Sevilla frente a Madrid», ha sido puesta de relieve por J. M. Lope Blanch ${ }^{12}$ a la hora de caracterizar el español americano, incluso ha sido propuesto sevillanismo como término mucho más sólido que el vagaroso (hazily) de andalucismo (sugerencia de Malkiel en 1972); son numerosas también las ocasiones en que $\mathrm{M}$. Alvar ${ }^{13}$ ha hablado de la «norma sevillana» como base de lo que en otros estudios se denomina «español atlántico», así como de la imagen de Sevilla que conquistadores y colonos llevaban por el Nuevo Mundo; finalmente, pese a su vuelta a posiciones poligenéticas sobre el español americano, también G. Salvador se declara partidario de la denominación sevillanismo ${ }^{14}$.

3. La intervención de Sevilla en la configuración inicial del habla americana no debe concebirse sólo como transmisión de rasgos y elementos lingüísticos surgidos en el valle bajo del Guadalquivir. Es sabido que a América llegaron dialectalismos peninsulares de diversos orígenes; algunos tienen clara filiación norteña, como la pronunciación asibilada de $/ \overline{\mathrm{r}} /$ o la del grupo $-\mathrm{tr}-$ : de amplia difusión (va desde Chile a México, con mayor, menor o nula presencia según las zonas), se creyó en un principio de raíz indígena ( $\mathrm{R}$. Lenz), hasta que A. Alonso ${ }^{\text {is }}$

12 El español de América, Madrid, Ed. Alcalá, 1968, pp. 47-48.

13 P. ej. en «Sevilla, macrocosmos lingüístico», Estudios filológicos y lingüísticos. Homenaje a A. Rosenblat, Caracas, 1974 , pp. 13-42.

14 «Discordancias dialectales en el español atlántico», I Simposio Internacional de Lengua Española (1978), Ed. del Excmo. Cabildo Insular de Gran Canaria, 1981, pp. 351-359.

15 «La pronunciación de «rr» y de «tr» en España y América», en Estudios lingüísticos. Temas hispanoamericanos, 3. ed., Madrid, Gredos, 1976, pp. 123-158. 
mostró su existencia en Rioja, Navarra y País Vasco: precisamente su mayor presencia se da en áreas donde hubo predominio de pobladores castellanos viejos o vascos (incluyendo la provincia argentina de Rioja); un origen semejante, aunque en condiciones de lenguas en contacto, parece tener el especial leísmo del español paraguayo o ecuatoriano; o las dislocaciones acentuales en los hiatos (páis, bául, etc.). En estos y otros casos el canal por donde tales fenómenos pasaron a América fue también Sevilla, pero de forma absolutamente pasiva: ninguno de esos fenómenos existía en la región, y ninguno llegó a arraigar (por el contrario, se dan situaciones opuestas por entero: así, en lo que hace a los hiatos vocálicos); su presencia en América y su ausencia en Andalucía muestran que en ningún momento entraron a formar parte de la koiné que se constituía, entre quienes esperaban la flota en Sevilla o Cádiz, sobre la base de la lengua del entorno (según opinión de Malmberg): pero también nos indica que no siempre los inmigrantes estaban dispuestos a suprimir sus propios rasgos dialectales en aras del castellano común nivelador.

La cuestión que aquí nos interesa es, sin embargo, otra: la de Sevilla como receptora y transmisora de diversos dialectalismos hacia América. La implantación del castellano en el valle del Guadalquivir desde el s. XIII (lo que luego ocurriría en el Reino de Granada nos atañe menos) fue una más de las consecuencias del repoblamiento ahí efectuado: los recién llegados traían sus propias formas lingüísticas romances, que muy pronto quedaron sin competencia ninguna al ser expulsados en masa los mudéjares a partir de 1264 (el elemento mozárabe había desaparecido hacía tiempo). El núcleo fundamental, y por tanto la lengua única que se asentó, era castellano; pero junto a ellos había gentes de otras procedencias: un conjunto relativamente denso de leoneses, y después grupos más o menos numerosos de gallegos, catalanes, etc., a más de los extranjeros, entre quienes predominaban portugueses e italianos (genoveses sobre todo). La Baja Edad Media fue un período de fuertes movimientos de población en Andalucía: tras los primeros poblamientos del XIII, que supusieron ya el contacto de hablas diversas y una primera nivelación, a finales de siglo se produce un retroceso claro (crisis económica e inseguridad fronteriza), que llevó incluso al regreso a sus tierras de origen de muchos colonos. La repoblación se intensificó de nuevo en el s. XIV $\mathrm{y}$, especialmente, en el XV, aunque en estas épocas tenemos muy pocos datos sobre el origen de los pobladores ${ }^{16}$. A finales del s. XV hay un nuevo aluvión de gentes de muy varia procedencia hacia Andalucía: la guerra de Granada en primer lugar, y luego la conquista de América y su colonización fueron los hechos que lo provocaron. Hay, pues, dos momentos cruciales para que se produzcan fenómenos de interferencia y nivelación lingüísticas: la segunda mitad del s. XIII y las postrimerías del XV (aparte el lento proceso de las etapas intermedias); en estas épocas el castellano de Andalucía, continuando viejos hábitos de la lengua, debió de ir asimilando elementos de otra filiación: esos elementos estaban ya integrados en el habla del Reino de Sevilla cuando se empieza a producir el flujo

16 M. González Jiménez, En torno a los origenes de Andalucia, Univ, de Sevilla, 1980. 
hacia el Nuevo Mundo recién descubierto, y muchos de ellos van a quedar implantados en la lengua alli desarrollada, en toda o en parte de su extensión. El habla de Sevilla sería, asi, responsable de la presencia en América de dialectalismos de diversa procedencia (leonesismos, etc.) pero que, en primer término, constituirian un caso aparente de "andalucismo» o "sevillanismo». Con ello se podría precisar mejor la aportación andaluza al habla americana, así como la siempre afirmada presencia del habla de todas las regiones españolas en América.

Para ello hemos de contar, naturalmente, con que el dialectalismo en cuestión sea antiguo en América (no llevado por las posteriores y modernas oleadas de emigrantes), y existiera en Andalucía al menos desde los primeros tiempos de la Conquista: sólo asi nuestra hipótesis tendrá fundamento empírico. Y eso es lo que falta por lo general: casi siempre hemos de contentarnos con saber que determinado hecho dialectal (en la mayoría de los casos, de tipo léxico) existe en Andalucía y América, junto a su zona de origen (tampoco las comprobaciones de su existencia son a veces muy fiables), de lo que podemos inferir la antigüedad de la relación. En otras ocasiones se trata simplemente de fenómenos que eran comunes en castellano clásico o medieval, y que, como arcaísmos, quedaron relegados a zonas relativamente marginales (León, Andalucía, América, etc.): ése es el caso de la pervivencia de la aspiración procedente de $f$-latina en amplias zonas del Oeste peninsular (la prolongación andaluza oriental es fruto directo de la Reconquista), y que existe, con más o menos fuerza, en varios puntos de América; lo mismo podemos decir de muchos de los «arcaísmos léxicos» americanos estudiados por I. Lerner (subsistan o no en la Península) ${ }^{17}$.

4. En este marco es donde ha de plantearse la cuestión de los «occidentalismos» del español americano: fue J. Corominas quien, en $1944^{18}$, afirmó que los occidentalismos (leonesismos, galleguismos, portuguesismos, etc.), sobre todo de tipo léxico, formaban un bloque más compacto y demostrable científicamente que los andalucismos fónicos (tesis ésta de la que Corominas se mostraba bastante escéptico). De este modo, según subraya Malkiel, se seguía mostrando el carácter históricamente dialectal de las hablas de América, pero ahora en una dirección nueva. Aunque diez años después Corominas rechazó algunos de los casos que habia aducido ${ }^{19}$, en varios artículos de su monumental Diccionario siguió defendiendo su propuesta básica, y en el Vol. IV de la 1. edición formó una lista de tales occidentalismos bastante más nutrida que la de meridionalismos (más significativo aún es el hecho al no haber aislado Corominas ninguna otra fuente dialectal de léxico americano). Por otra parte, los recuentos demográficos de BoydBowman parecen apoyar las constataciones de Corominas: el porcentaje de asturianos, leoneses y extremeños (sin contar portugueses y gallegos) superaba en el siglo XVI al de castellanos viejos entre los marchados a América.

17 Arcaísmos lexicos del español de América, Madrid, Insula, 1974.

18 "Indianorrománica», Revista de Filologia Hispánica, VI, 1944, pp. 1-35, 139-175 y 209-254.

19. «Falsos occidentalismos americanos», Boletín de Filologia de la Universidad de Chile (Homenaje a R. Oroz), VHI, 1954-55, pp. 65-70. 
Las investigaciones de Corominas han tenido, hasta el momento, escasas continuaciones. En el apartado de «portuguesismos» han surgido algunos nuevos elementos de interés: así, los estudios de J. Pérez Vidal ${ }^{20}$ mostraron cómo las Canarias, ya bastante impregnadas de portuguesismo, transmitieron al español de América numeroso vocabulario de origen luso; por otro lado, G. de Granda ${ }^{21}$ ha ampliado las tradicionales vías de entrada de portuguesismos en América (según G. Salvador ${ }^{22}$ : marinería, emigrantes gallegos, brasileñismos en el Río de la Plata), a las que además cree de menor relevancia, con otras, bien de carácter indirecto: portuguesismos en dialectos españoles (leonés, extremeño, andaluz occidental, canario) que llegan a América, o directo: emigración de portugueses a la América española en los siglos XVI y XVII (pese a estar oficialmente prohibida), y hablas criollas basadas en el portugués de los esclavos negros llevados a los dominios españoles. Como vemos, Granda introduce al andaluz como puente de lusismos (¿por qué no de occidentalismos en general?) hacia América; para ello se basa en los estudios de Alvar surgidos del A.L.E.A. ${ }^{23}$, en los que se muestran las numerosas concomitancias léxicas entre Andalucía, sobre todo su extremo más occidental, y las hablas portuguesas; ello es fruto no sólo de la situación fronteriza sino también de situaciones históricas muy antiguas (dominio portugués sobre zonas de Huelva en el s. XIII, etc.); como es natural, Granda destaca la importancia de esta zona andaluza en la constitución de la koiné americana (así, señala cómo hasta 1520 el 38,7\% de los marineros identificados por BoydBowman procedía de Huelva y el $24,4 \%$ de Sevilla). Más reciente es el estudio de T. Sandru Olteanu ${ }^{24}$, en el que se intenta determinar el mayor o menor peso de las distintas zonas peninsulares en el léxico americano: sus conclusiones son contrarias a las de Corominas, pues estima que la proporción de occidentalismos es escasa (rechaza, además, la mayoría de los propuestos por Corominas), y vuelve a considerar predominante la aportación de meridionalismos, si bien éstos han de matizarse, ya que en la época de la Conquista el léxico andaluz apenas si se diferenciaba del castellano; la autora no hace ninguna alusión al posible papel del andaluz como transmisor de otros dialectalismos, limitándose a señalar las coincidencias de vocabulario entre unas zonas y otras.

La actuación del andaluz en la entrada de voces portuguesas en América ha de descartarse casi por entero: el mismo Alvar señala que casi todos los lusismos léxicos que encuentra son modernos y de carácter fronterizo, sin ninguna raigambre histórica (tampoco dejó descendencia lingüística el núcleo de portugueses del Algarve asentados en Jerez en 1264). Sólo en los casos de buraco (documentado

20 «Las Canarias, vía de introducción de portuguesismos en América», Actas do Colóquio de Estudos etnográficos «Dr. Leite de Vasconcelos», Porto, 1959-60, III, pp. 359-367.

21 "Acerca de los portuguesismos en el español de América», en Estudios lingüisticos hispánicos, afrohispánicos y criollos, Madrid, Gredos, 1978, pp. 139-156.

22 «Lusismos», Enciclopedia Lingüística Hispánica, II, Madrid, 1967, pp. 239-261.

23 En especial «Portuguesismos en andaluz», Weltoffene Romanistik. Festschrift A. Kuhn, Innsbruck, 1963 , pp. 309-324.

24 Ver art. cit. en n. 9. 
en portugués en el s. XVI, muy extendido hoy en el N.O. de España, y vivo en Sto. Domingo y Argentina), abanar y abanador (para Corominas «vivo en Canarias y otras partes»), margullo(n), todos ellos documentados sólo en Huelva, podría pensarse en tal papel transmisor (pero faltan datos antiguos). Por su parte, Alvar se muestra convencido de que todos los compuestos españoles con peje ( $<$ pisce) como primer elemento son de origen occidental, mientras que Corominas suma al elemento leonés el mozárabe (por hallarse peje en M. Alemán), base sobre la que se difundió abundantemente tal forma en América. Por último, cardume(n) puede haber tenido Andalucía como escalón intermedio entre su raíz gallego-portuguesa y su presencia americana actual: en 1607 lo usa en América el andaluz Juan de Castellanos, y en el s. XVIII lo emplean escritores sevillanos; sin embargo, su carácter de voz marinera lo ha llevado más allá de los límites habituales en este grupo de lusismos, y así aparece también en Málaga y Almería.

La posibilidad de que el andaluz fuera el origen inmediato de algunos occidentalismos del español americano, recogida por Lapesa desde la 8 a edición de su Historia de la Lengua Española, viene apoyada por el hecho de que muchos de esos occidentalismos (tanto entre los señalados por Corominas como por Sandru Olteanu) han sido localizados en las hablas andaluzas, en especial hacia el Oeste $^{25}$. Esta coincidencia no es casual: es, pues, lícito pensar en el habla del Reino de Sevilla, en el habla andaluza occidental, como receptáculo durante la Edad Media de formas del viejo dialecto leonés, formas que fue luego vertiendo en su proyección americana; a este respecto, conviene recordar que al viejo núcleo occidental (leonés, gallego, etc.) de la época de la reconquista sevillana hay que añadir la comunicación posterior entre estas zonas, nunca interrumpida luego, por medio del eslabón extremeño. Nada impide por otra parte que algunos, o muchos, de esos occidentalismos llegaran directamente a América: según los recuentos de Boyd-Bowman el porcentaje de extremeños emigrados al Nuevo Mundo fue, desde 1493 a 1600 , superior al de castellanos viejos (16,4\% frente a $14 \%$ ); a ellos habría que sumar el de leoneses y asturianos $(6,5 \%: 5,9 \%$ de los primeros frente a $0,6 \%$ de los segundos); ese flujo de «occidentalismos directos» (que podrían existir ya en Andalucía, o no haber llegado aún a ella) no tiene por qué contradecir nuestros postulados, aunque haría regresar la cuestión del dialectalismo americano a los términos señalados por Corominas. Naturalmente, para tomar una decisión firme, en pro o en contra, acerca de la hipótesis propuesta habrá que contar con documentación más rica de la que nos vemos obligados a manejar, especialmente de época medieval y clásica.

Como quedó señalado más arriba, casi todos los elementos que se manejan a la hora de establecer este tipo de relaciones son léxicos. Corominas, sin embargo, alude a dos supuestos leonesismos gramaticales: las traslaciones acentuales en la $1^{\text {a }}$ y $2^{\text {a }}$. personas plurales del presente de subjuntivo (p. ej.: váyamos, hágais, etc.), y la inversión del orden de palabras en las construcciones más nada

25 Es lógico que Corominas desconociera tal circunstancia en 1954, cuando la dialectología andaluza estaba aún en sus inicios; pero no es tan natural que lo siga haciendo en 1980, al volver a editar el Diccionario. 
y más nadie. El primer fenómeno suele ser considerado vulgarismo sin adscripción regional concreta (así en Lapesa); Corominas, por el contrario, lo documenta en hablas gallego-portuguesas y leonesas y lo cree antiguo (frente a la modernidad del uso idéntico catalán); los ejemplos literarios del s. XIX se dan, sobre todo en escritores andaluces o gallegos; el A.L.E.A. (T. VI, Mapa 1816) muestra una situación muy curiosa: mientras séamos-séais, háyamos-háyais aparecen dispersos un poco por toda Andalucía, hágamos-hágais y véngamos-véngais se concentran sobre todo en la Andalucía Occidental; en América el fenómeno es muy general. En cuanto al segundo, ya señalado por Cuervo para Bogotá, es general en toda Andalucía (A.L.E.A., T. VI, Mapas 1876-1877), con una curiosa escasez de presencia en Huelva para la construcción más nunca; Corominas recuerda su existencia en León y Galicia, pero no hay muchas más referencias sobre ello; de todos modos, no hay que olvidar que ha sido documentado en Aragón ${ }^{26}$.

En algunos casos el lazo que une las hablas occidentales peninsulares de tipo leonés y andaluz con el español americano cuenta sólo con documentación antigua: es lo que ocurre con acezar, 'jadear', arcaísmo ya para el Diccionario de Autoridades y vivo hoy sólo en Cáceres, Salamanca y Tras-os-Montes (según Corominas), del cual las citas clásicas proceden de autores leoneses, salvo Nebrija y el sevillano Hojeda. Quizá podamos decir lo mismo de frisa, 'tela gruesa de lana', cuyo uso por M. Alemán en el Guzmán de Alfarache puede constituir el puente entre León y Cáceres y América; o de trast(r)abillar(se), empleado por asturianos y salmantinos, pero también por el sevillano Juan de Castellanos.

Mucho más habitual es la presencia de estas voces leonesas y americanas en alguno de los clásicos vocabularios de andalucismos: el de Toro y Gisbert y el de Alcalá-Venceslada ${ }^{27}$, que, pese a sus numerosas deficiencias de método y recogida de datos, siguen siendo imprescindibles; en ellos, sin embargo, la localización precisa se hace difícil. De esta forma, podemos señalar la presencia común en las zonas que consideramos de: altozano, 'atrio de iglesia' (según Toro), voz que, sin embargo, difícilmente puede considerarse dialectal; andancio, 'enfermedad epidémica' (bajo la forma, también leonesa, de andancia, según Alcalá-Venceslada, y que aparece también en América); angaripola, 'lienzo basto estampado' (según A.-V. indica un aparejo de mulas: ya se daba como andaluz en 1693, según recoge Gili y Gaya en su Tesoro lexicográfico); barrial, 'barrizal', cuya documentación antigua es toda leonesa, salvo sus apariciones en Nebrija y F. Caballero, de quien la recoge Toro; es este último también quien da como andaluz el leonesismo botar, 'echar', pero es más dudoso; en cambio, es forma muy viva en Andalucía candela, 'lumbre, fuego' (lo cual fue señalado ya por $D A$ ut., que la consideraba anticuada), y cuyo carácter leonés se atestigua ya en su presencia en la traducción del Fuero .Juzgo del s. XIII; carrada, 'carretada', se da en Asturias, Andalucia y América, pero pudiera ser creación independiente en cada zona; cobija, 'ropa y abrigo de cama', de antecedentes salmantinos, era ya utilizada

26. M. Alvar, El habla del Campo de Jaca, Salamanca, 1948, \$ 75.

27 Vocabulario andaluz, 2: ed., Madrid, 1951 (cito por la reimpresión publicada por la Ed. Gredos en 1980). 
en el Siglo de Oro casi sólo por andaluces (fray Luis de Granada, Juan de Castellanos, M. Alemán); (d)esmorecerse, con diversos sentidos, está presente en todo el ámbito leonés, Andalucía, Canarias y América; engerido, 'alicaído', andalucismo según el $D A u t$. y vivo también en Extremadura: se encuentra ya en el Cancionero de Baena; esculcar, 'registrar', vieja voz castellana arrinconada en el Oeste, y en Andalucía según A.-V.; de frangollar, 'quebrantar el grano de trigo', que Corominas da también como andaluz (pero sin citas), se aduce en Toro frangollón, 'que hace las cosas de prisa y mal' (también en A.-V., quien aduce otras voces de la familia, alguna de ellas con el mismo sentido también en América); furnia, 'cueva, sima', de clara raigambre leonesa, es considerado también andaluz por A.-V.; menos claros son pálpito, 'presentimiento', de la que Corominas duda si es leonesa (o castellana vulgar anticuada) o brasileñismo en el Río de la Plata (pero también se presenta en México), y que A.-V. atestiguó en Andalucía; y pata, 'igual', dada para Andalucía por Toro. Corominas coloca en la misma serie al portuguesismo laja, 'piedra lisa, poco gruesa', quizá extendido al uso náutico (y de aquí a América) por medio de su paso a la lengua de Sevilla (aparece en M. Alemán); y a saber = 'soler', para el que, tras un crítico análisis de las conclusiones de M. R. Lida, propone un origen leonés o gallegoportugués (en la época medieval sólo aquí se documenta inequívocamente) y una prolongación andaluza (se da en López de Gómara, Mira de Amescua). En Sandru Olteanu aparecen como «occidentalismos» voces que A.-V. atestigua para Andalucía: aparte de cangalla, que veremos luego, encontramos espernancarse (bajo la forma espernacarse, 'abrirse las piernas'); huesera, 'osario'; mortiño, 'mirto, arrayán' (en A.-V. bajo la forma mortiñera).

Los descubrimientos realizados por el A.L.E.A. y los estudios léxicos que han desarrollado algunas de sus facetas han venido a añadir nuevos datos a la tesis que defendemos: varios de los occidentalismos americanos citados por Corominas y que no habian sido recogidos con anterioridad aparecen, y algunos con extraordinaria vitalidad, en Andalucía; su localización, ahora sí mucho más precisa, apoya también la imagen de nuestro dialecto como escalón hacia América. Así, bago, 'grano de uva', presente en todo el Oeste peninsular (y en el N. de Huelva) tiene como derivado bagazo, 'orujo de la uva' en Galicia, Portugal y Cáceres, 'orujo prensado' en Canarias, y 'zumo, residuo' en diversas zonas americanas: en la forma metatizada gabazo y con el valor de 'escobajo de la uva' se encuentra en el S. y E. de Huelva (A.L.E.A., I, Mapa 202; Corominas ya lo había reflejado); maza con el valor de 'cubo de la rueda del carro' se encuentra en el Oeste peninsular, en Andalucía salvo las provincias más orientales y en América, pero también aparece en Murcia y Burgos, y según A. Zamora ${ }^{28}$ es un arcaísmo castellano; calabozo, 'podadera', de raíz y existencia leonesa, se documenta por primera vez en Nebrija y hoy ocupa un área compacta en las tres provincias andaluzas occidentales, con penetración hacia Córdoba y Málaga: de ahí el origen de su presencia en Cuba; cangallo y cangalla (en general, con yeísmo moderno, pero en algún punto de Huelva con - - -) son formas gallego-portuguesas

28 Dialectología española, 2. ed., Madrid, Gredos, 1970, pp. 336, 343 у 426. 
y leonesas derivadas de canga (palabra ésta que Corominas excluye de Andalucía en «Indianorrománica» pero que presenta como andaluza, 'yunta de animales', en el Diccionario): para Corominas, en Andalucía sólo existe cangallo con el valor figurado de 'persona despreciable o de mala figura', pero también existe cangalla en el O. de Huelva para 'instrumento para transportar haces': todo ello lo iguala a las formas y valores americanos; carozo parece tener también origen leonés: con el valor de 'hueso de fruta' se encuentra en hablas salmantinas, extremeñas y americanas, habiendo pasado en estas últimas a designar un cierto fruto encerrado en una corteza, mientras que con el de 'centro de la espiga del maiz' aparece en gallego y portugués, asturiano occidental, andaluz (del centro de Sevilla hacia Cádiz) y canario (dada esta situación y reparto, Alvar cree que en Andalucía se trata de importación moderna, llegada con el reciente cultivo); lama, 'fango', se documenta en la Península en Portugal, Galicia, León y Asturias (para Corominas el uso toponímico de lama se reduce a estas zonas), pero en el Siglo de Oro debía tener mayor extensión: curiosamente, la mayoría de ejemplos aducidos por Corominas son de sevillanos del s. XVII (como M. Alemán), aparte de algunos sorianos, a lo cual parece corresponder su presencia hoy en Huelva y O. de Sevilla, zona que constituiría nuevamente su trampolín hacia América.

5. No siempre la dirección de la relación léxica es la que hemos venido indicando: hay ocasiones en que un término nacido en el Sur de la Península (casi siempre se trata de mozarabismos) llega a América dentro del conjunto de «meridionalismos» o «andalucismos» léxicos (de los que Corominas ofrece una lista en el Vol. IV de la 1. edición de su Diccionario, según ya dijimos), y a la vez se difunde hacia el Norte de España, pudiendo incluir el área gallego-portuguesa. Es lo que parece haber ocurrido con los mozarabismos chicharo y chiquero. En otros casos la situación es más compleja: así, en frijol parecen combinarse, según Corominas, los orígenes gallego-portugués y mozárabe (aparte del problema de la acentuación de este vocablo).

\section{Conclusión}

Los hechos aquí presentados distan mucho de ser los únicos que podrían aducirse con el propósito que nos ha guiado. Sólo se han expuesto aquellos casos en que la relación parecía clara; en muchos otros es precisa una más detallada investigación. Naturalmente, estudios de este tipo siguen siendo necesarios: y ello tanto sobre fuentes y repertorios léxicos ya conocidos como sobre otros muchos que podrían despojarse con fruto. El objetivo de este análisis no ha sido otro que el de intentar seguir una línea ya sugerida por algunos estudiosos y que parece extraordinariamente rica en implicaciones para la historia del español de uno y otro lados del Atlántico. 